\title{
The Inhibition of Insulin Secretion from the Perfused Rat Pancreas after Thyroxine Treatment*
}

\author{
S. Lenzen, H. G. Joost and A. Hasselblatt \\ Institut für Pharmakologie und Toxikologie, Universität Göttingen, Göttingen, Federal Republic of Germany
}

Summary. Thyroxine treatment did not significantly affect the immediate insulin secretory response of the perfused rat pancreas, but it inhibited the late phase of D-glucose-induced insulin secretion. Thyroxine treatment did not inhibit D-glyceraldehyde-, D-mannose-, and tolbutamide-induced insulin release from the perfused pancreas. An increase in the D-glucose concentration of the perfusion medium as well as feeding of the rats did not restore insulin secretion after thyroxine treatment. The inhibition of D-glucose-induced insulin release in response to thyroxine treatment was reversed after addition of either D-glyceraldehyde, dihydroxyacetone, DL-glyceric acid, pyruvate, or $\alpha$-ketobutyrate to the perfusion medium. Tolbutamide, L-glucose, D-fructose, D-mannose, L-lactate, and propionic acid were not able to overcome the inhibition of D-glucose-induced insulin secretion. Except for $\alpha$-ketobutyrate all substances which were effective in reversing the inhibition of D-glucose-induced insulin release were glycolytic intermediates. Comparing the glycolytic $\alpha$-ketoacid pyruvate and the non-glycolytic ketoacid $\alpha$-ketobutyrate, the only part common to both substances was the ketoacid moiety. It is concluded from these findings that the ketoacid moiety of the $\alpha$-ketoacids plays an important role in reversing the effect of thyroxine on D-glucose-induced insulin release.

Key words: Rat pancreas perfusion, insulin secretion, thyroxine treatment, D-glucose, D-glyceraldehyde, $\mathrm{D}$-mannose, tolbutamide, L-glucose, $\mathrm{D}$-fructose, dihydroxyacetone, DL-glyceric acid, pyruvate, L-lactate, propionic acid, $\alpha$-ketobutyrate.

\footnotetext{
* This work was presented in part at the $11^{\text {th }}$ Annual Meeting of the European Association for the Study of Diabetes, Munich, September, 1975
}

Since the experiments of Houssay thyroid hormones have been generally looked upon as diabetogenic hormones [1].

It is now thirty years ago since Houssay concluded from his studies on the dog that "the pancreas of an animal with thyroid or metathyroid diabetes secretes little or no insulin, as can be shown by grafting it into the circulation of a diabetic dog" [1].

These early experiments were followed by many investigations on the diabetogenic effect of thyroid hormones, with rather controversial results [2]. Since we have shown that thyroxine treatment inhibits insulin secretion from the perfused rat pancreas [3], we have described some of the aspects of the inhibitory effect of thyroxine on insulin release [4] and discussed some of the related literature in detail [2].

It is the purpose of this publication to define further the inhibitory effect of thyroxine treatment on insulin secretion from the perfused rat pancreas. Two main aspects will be discussed in detail: (a) the selectivity and (b) the reversibility of the inhibitory effect of thyroxine and its implications for glucose-, glyceraldehyde-, mannose-, and tolbutamide-induced insulin release from the pancreas. Some of the results have been presented in abstract form [5].

\section{Materials and Methods}

\section{Chemicals}

Pure rat insulin was kindly supplied by Novo $\mathrm{GmbH}$, Mainz, tolbutamide by Farbwerke Hoechst AG, Frankfurt. 125-I-labelled insulin was obtained from Behringwerke AG, Frankfurt, (-) thyroxine (sodium salt) and bovine albumin (fraction V) were from Serva, Heidelberg; D-glyceraldehyde, L-glucose, dihydroxyacetone, L-lactate, propionic acid, and 

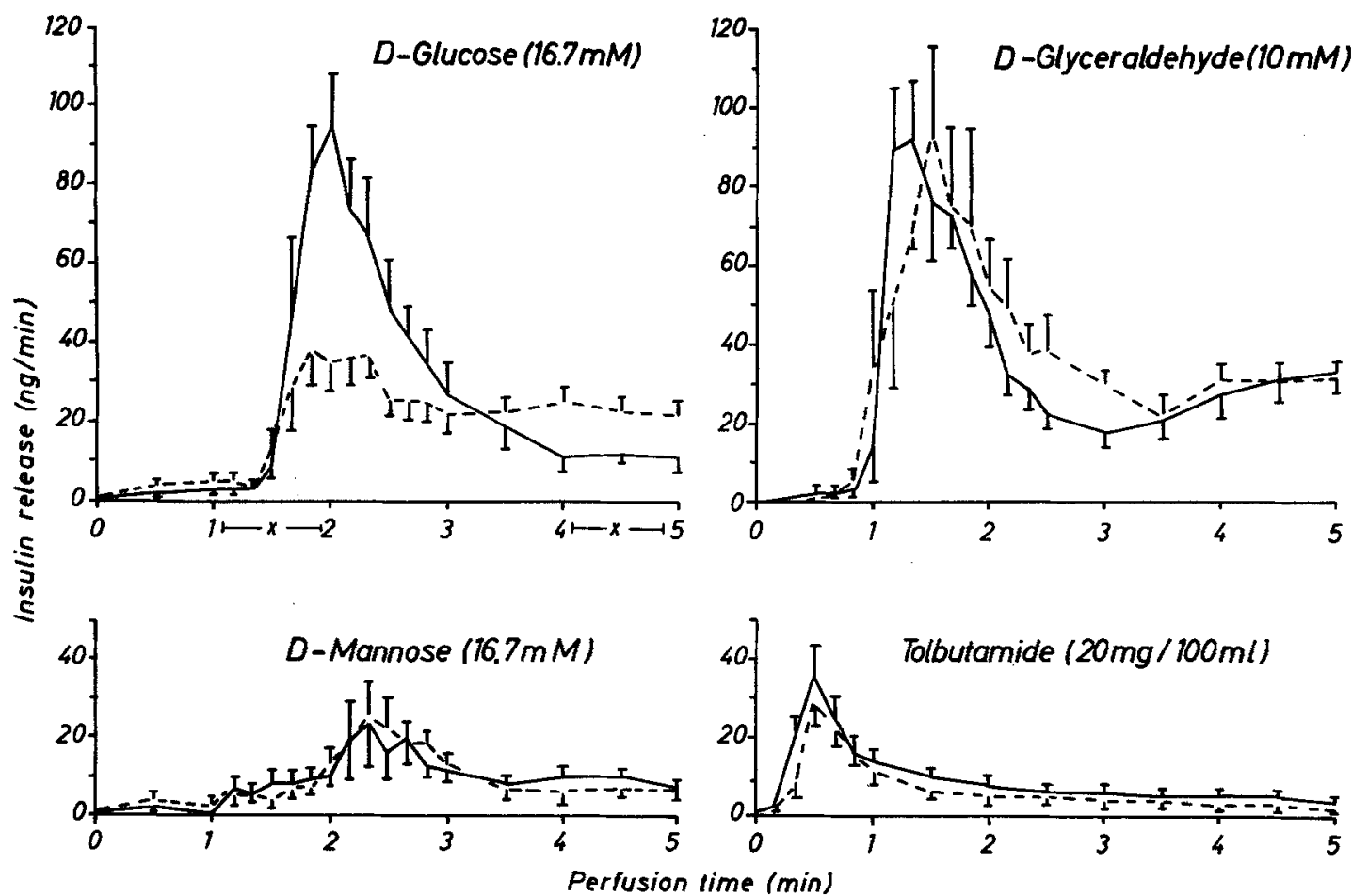

Fig. 1. The effect of D-glucose, D-glyceraldehyde, $D$-mannose, and tolbutamide on the immediate insulin secretory response (1-5 min) of the perfused pancreas from thyroxine $\left(600 \mu \mathrm{g} / \mathrm{kg} \mathrm{b}\right.$. wt.) treated rats $\left(\mathrm{O}_{-}-\mathrm{O}\right)$ and controls $\left(\mathrm{O}_{-}-\mathrm{O}_{-}-\mathrm{O}\right)$. Mean $\pm \mathrm{SEM}$. ${ }^{\mathrm{x}} \mathrm{p}<0.05$ as compared to controls
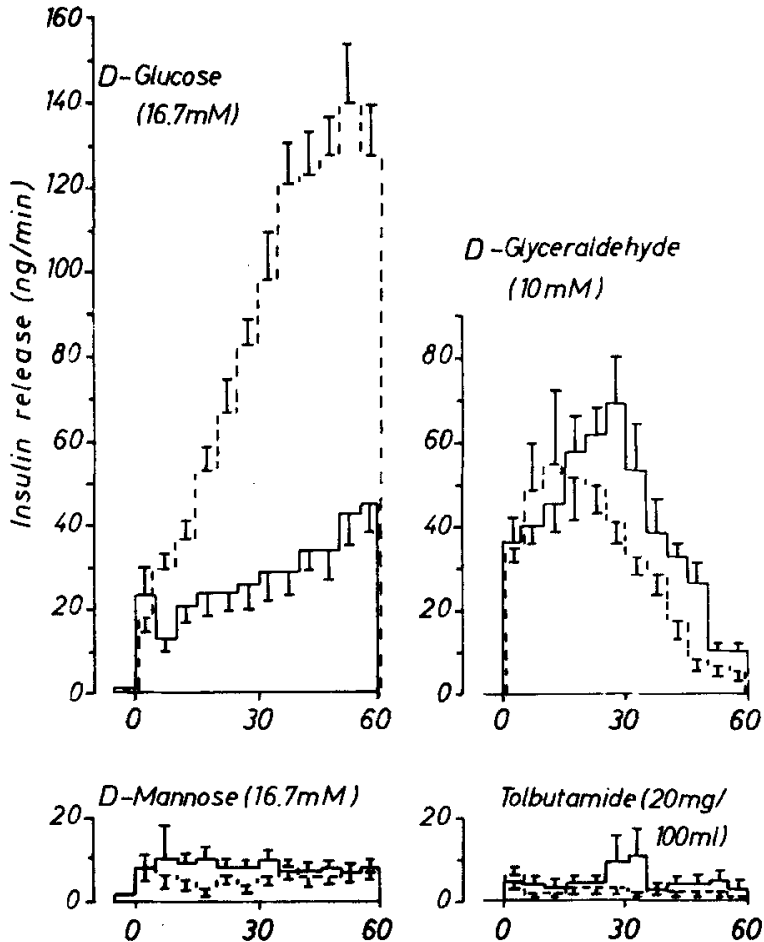

Fig. 2. The effect of D-glucose, D-glyceraldehyde, D-mannose, and tolbutamide on insulin secretion from the perfused pancreas from thyroxine $(600 \mu \mathrm{g} / \mathrm{kg} \mathrm{b}$. wt.) treated rats $(\mathrm{O}-\mathrm{O}-\mathrm{O})$ and controls $(0--0--O)$. Mean \pm SEM $\alpha$-ketobutyrate were from Sigma Chemical Company, St. Louis, USA; D-glucose, D-mannose, D-fructose, DL-glyceric acid, pyruvate and all other substances of analytical grade were from Merck AG, Darmstadt.

\section{Experimental Design}

Male Wistar rats $(200-250 \mathrm{~g})$ were treated with thyroxine $(600 \mu \mathrm{g} / \mathrm{kg} \mathrm{b}$. wt./day, for five days) or an equivalent volume of saline. On the sixth day the pancreas and the adjacent part of the duodenum, the spleen, and the stomach were removed from 24 hour fasted or fed rats according to the method of Grodsky et al. [6], with slight modifications as described in detail in this journal before [4]. Immunoreactive insulin was determined by the method of Zaharko and Beck [7].

\section{Calculations}

Results were tested for significance with Student's t-test and presented as the mean \pm S. E.M. For clarity mean values for 60 minutes of perfusion and levels of significance are given only in Table 1 . 


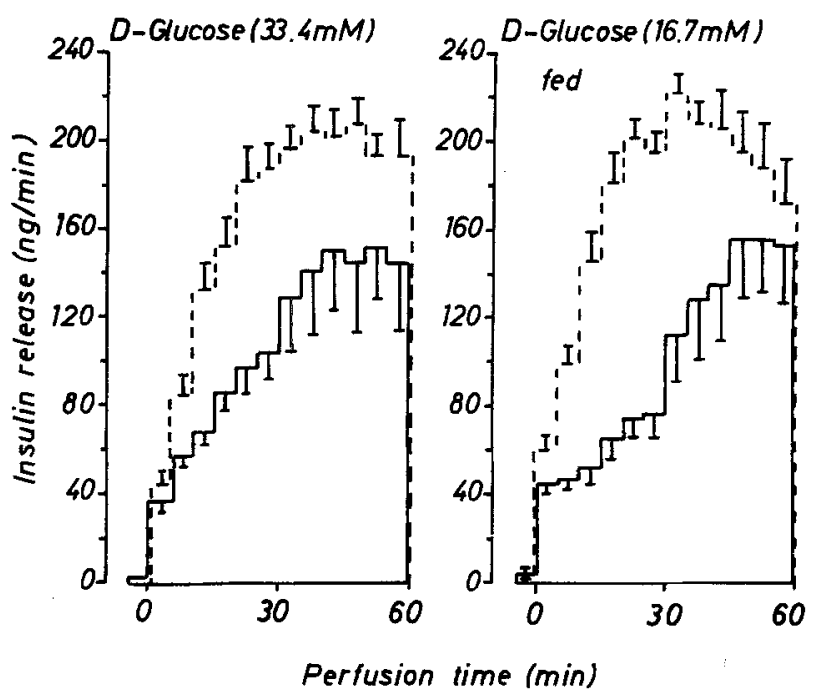

Fig. 3. The effect of high D-glucose concentration and feeding on insulin secretion from the perfused pancreas of thyroxine $(600 \mu \mathrm{g} / \mathrm{kg} \mathrm{b}$. wt. $)$ treated rats $(\mathrm{O}-\mathrm{O}-\mathrm{O})$ and controls $(\mathrm{O}--\mathrm{O}---\mathrm{O}) \cdot$ Mean \pm SEM

\section{Results}

Thyroxine treatment $(600 \mu \mathrm{g} / \mathrm{kg}$ b. wt./day, for 5 days) had only a moderate stimulatory effect on the immediate insulin secretory response of the perfused rat pancreas to D-glucose (16.7 mM) (Fig. 1).

Thyroxine treatment reduced significantly D-glucose-induced insulin secretion during the late phase of release from the perfused pancreas (Fig. 2 and Table 1).

As compared to D-glucose $(16.7 \mathrm{mM})$ the immediate insulin secretory response to D-glyceraldehyde $(10 \mathrm{mM})$ appears $20-30$ seconds earlier and the response to tolbutamide $(20 \mathrm{mg} / 100 \mathrm{ml}) 90-100$ seconds earlier, whereas the response to D-mannose $(16.7 \mathrm{mM})$ appears $30-40$ seconds later than the secretory response to D-glucose (Fig. 1). Furthermore, only D-glucose was able to induce a permanently increasing late phase of insulin release (Fig. 2). During the whole perfusion period of 60 minutes (Fig. 2) insulin release induced by $\mathrm{D}$-glyceraldehyde, tolbutamide, and D-mannose during the immediate secretory response, as well as during subsequent release, was not inhibited by thyroxine treatment (Figs. 1 and 2). There was even a slight, but not significant, stimulation of insulin secretion from the perfused pancreas in response to D-glyceraldehyde, D-mannose, and tolbutamide (Table 1).

We have investigated if an increase in glucose concentration in the perfusion medium or feeding of the animals before the experiments results in a reversal of the inhibition of D-glucose-induced insulin release after thyroxine treatment. Though both in-

\section{D-Glucose $(16.7 \mathrm{mM})$}

$+\alpha-$ Ketobutyric Acid $(10 \mathrm{mM})$

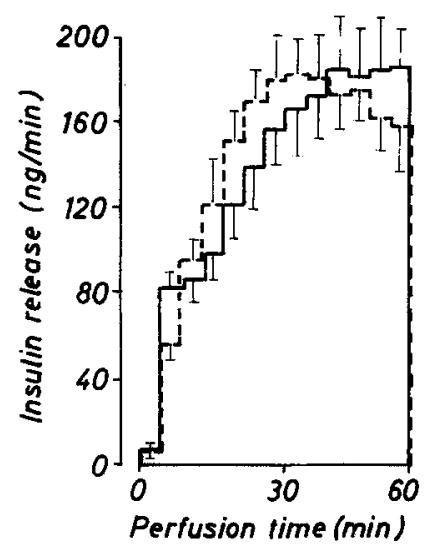

Fig. 4. Reversal by $\alpha$-ketobutyrate of the inhibitory effect of thyroxine treatment on D-glucose-induced insulin secretion from the perfused pancreas of thyroxine $(600 \mu \mathrm{g} / \mathrm{kg} \mathrm{b}$. wt.) treated rats $(\mathrm{O}-\mathrm{O}-\mathrm{O})$ and controls $(\mathrm{O}--\mathrm{O}--\mathrm{O})$. Mean \pm SEM

creased D-glucose concentration $(33.4 \mathrm{mM})$ and feeding of the rats further stimulated insulin release in controls, as well as after thyroxine treatment (Fig. 3 and Table 1), a significant inhibition of D-glucose-induced insulin release could be demonstrated in both cases (Fig. 3 and Table 1). The ability of several substances to reverse the inhibition of D-glucose-induced insulin release after thyroxine treatment was investigated. Most of these substances have been shown at some time or another not to induce insulin release from the perfused rat pancreas in the absence of glucose from the perfusion medium. We can confirm that the following substances did not induce insulin release in the absence of glucose: L-glucose $(16.7 \mathrm{mM}), \mathrm{D}-$ fructose $(16.7 \mathrm{mM})$ [8], dihydroxyacetone $(10 \mathrm{mM})$ [9], DL-glyceric acid (10 mM), pyruvate $(10 \mathrm{mM})[6]$, L-lactate $(10 \mathrm{mM})$ [10], and propionic acid $(10 \mathrm{mM})$. In contrast to another report, we noticed a very small stimulatory action of $\alpha$-ketobutyrate $(10 \mathrm{mM})$, even smaller $(50 \%)$ than that of D-mannose $(16.7 \mathrm{mM})$ (Table 1) [11]. Additionally we included in our study the D-glucose independent insulin secretagogues Dglyceraldehyde $(10 \mathrm{mM}), \mathrm{D}$-mannose $(16.7 \mathrm{mM})$ [8], and tolbutamide $(20 \mathrm{mg} / 100 \mathrm{ml})[4,12]$.

The supplementation of the perfusion medium, in addition to D-glucose $(16.7 \mathrm{mM})$, with D-glyceraldehyde $(10 \mathrm{mM})$, dihydroxyacetone $(10 \mathrm{mM})$, DL-glyceric acid $(10 \mathrm{mM})$, pyruvate $(10 \mathrm{mM})$, and $\alpha$-ketobutyrate (10 mM) (Fig. 4) completely abolished the inhibition of D-glucose-induced insulin secretion after thyroxine treatment (Table 1). Tolbutamide $(20 \mathrm{mg} / 100 \mathrm{ml})$ reduced the inhibition (Table 1), whereas L-glucose (16.7 mM), D-fructose 
Table 1. The effect of D-glucose, some other D-glucose independent stimulators of insulin secretion and several other non stimulating substances on insulin secretion from the perfused pancreas of thyroxine $(600 \mu \mathrm{g} / \mathrm{kg} \mathrm{b}$. wt.) treated rats and controls

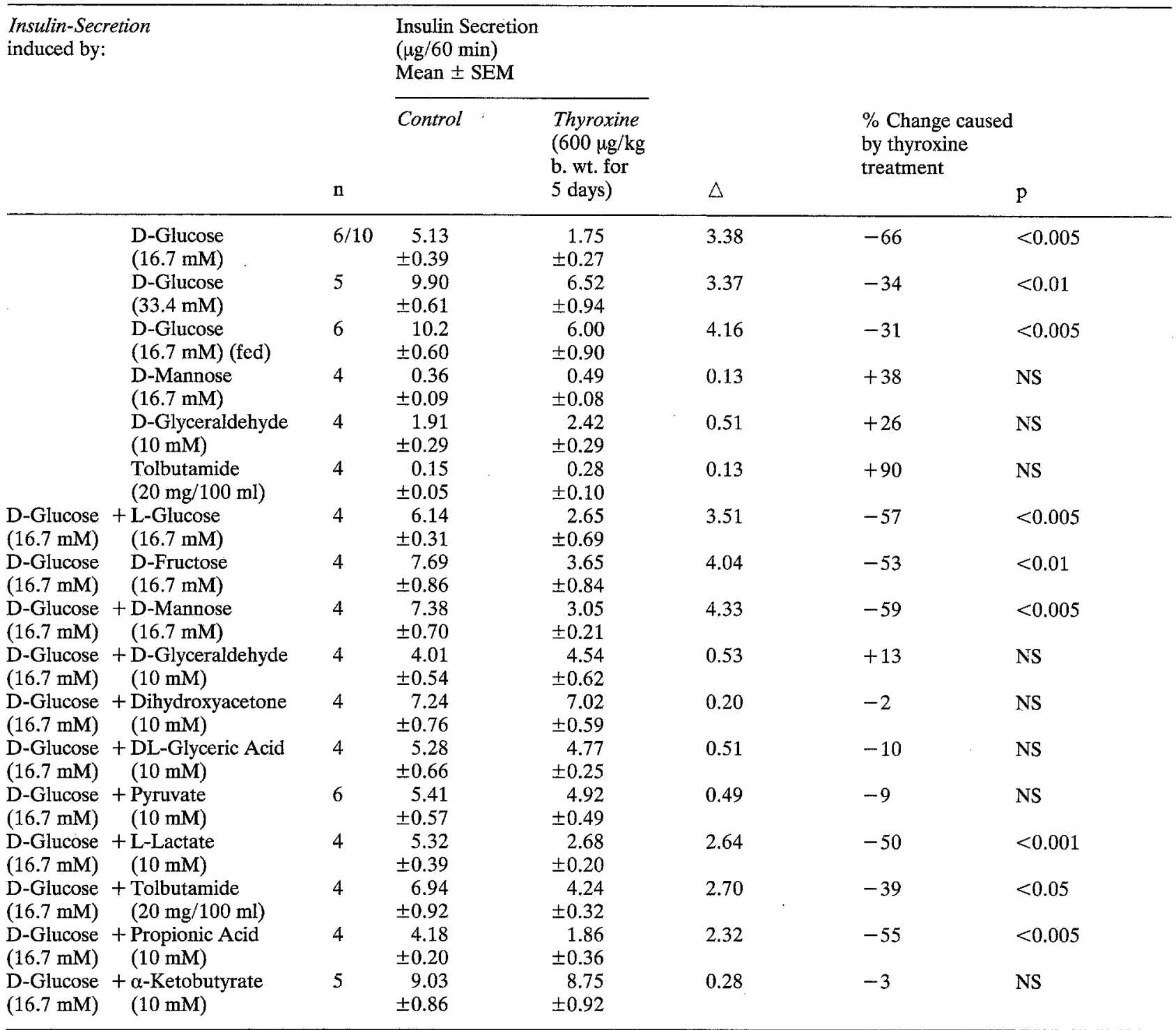

(16.7 $\mathrm{mM}), \mathrm{D}$-mannose $(16.7 \mathrm{mM})$, L-lactate $(10$ $\mathrm{mM})$, and propionic acid $(10 \mathrm{mM})$ were not able to reverse the inhibition of thyroxine treatment on insulin secretion from the perfused rat pancreas.

\section{Discussion}

Hyperthyroidism is associated with an increased incidence of diabetes [1]. In man the large amount of controversial literature [2], as a result of differences in experimental design and criteria for selection of patients, does not provide on explanation [2]. In laboratory animals the difficulties can be overcome by administration of thyroxine. Experimental hyper- thyroidism, very similar to the state found in hyperthyroid patients, can be induced [2].

Thyroxine treatment interfered only with the late phase of glucose-induced insulin release (Fig. 2). The immediate insulin secretory response remained intact (Fig. 1). In this respect thyroxine differs markedly from other inhibitors, which affect both the immediate and the late phase of insulin release. The intact immediate response indicates that glucose is recognized by the pancreatic B-cell, although changes in the transition of the initial signal may be induced by thyroxine treatment. This view is supported by the fact that inhibition of insulin release induced by thyroxine was reversible. 
Neither feeding nor an increased glucose concentration could prevent thyroxine-induced inhibition, though insulin release from the pancreas of thyroxine treated rats, as well as of control animals, was clearly stimulated (Fig. 3 and Table 1). In contrast to many other inhibitors of insulin secretion the inhibition induced by thyroxine is specific for glucose-induced insulin release. The secretory action of pharmacologic agents, like tolbutamide [4], or physiologic stimúlators, like glyceraldehyde and mannose, was definitely not inhibited (Figs. 1 and 2). After treatment with lower doses of thyroxine, the stimulatory effect of tolbutamide was significantly higher than in controls [4]. This specificity may relate to the fact that glucose is the only stimulator which induces a permanently increasing late phase insulin release from the pancreas (Fig. 2). The characteristics of the inhibitory effect of thyroxine allow the conclusion that the inhibition of insulin release induced by this hormone is selective for the late phase of glucose-induced insulin release from the perfused pancreas.

The results presented here require some comments on glucose-induced and glyceraldehyde-induced insulin secretion. In several publications similar dynamics of insulin release from the perfused rat pancreas $[9,13]$ and from perifused mouse islets [14], in response to $\mathrm{D}$-glucose and $\mathrm{D}$-glyceraldehyde, have been described. In earlier experiments we noticed that the immediate insulin secretory response, as well as the late phase of hormone release, induced by D-glucose or D-glyceraldehyde, differed markedly from each other [15] (Figs. 1 and 2).

These findings allow the conclusion that glyceraldehyde, as well as tolbutamide and mannose, can easily be distinguished from each other, as they induced different immediate insulin secretory responses of the pancreas during the first few minutes of perfusion (Fig. 1). However, none of these secretagogues shared the ability of glucose to induce a permanently increasing late phase insulin release from the pancreas during the whole stimulation period of one hour (Fig. 2).

Thyroxine treatment did not reduce glucosestimulated insulin release when the perfusion medium was supplemented with D-glyceraldehyde, DL-glyceric acid, dihydroxyacetone, pyruvate, or $\alpha$-ketobutyrate. The ability of these substances to overcome the inhibition after thyroxine treatment is not related to the insulin secretory potency of these substances. All these substances, except for $\alpha$-ketobutyrate, are glycolytic intermediates. However, the fact that both glyceraldehyde and dihydroxyacetone (Table 1) can overcome the inhibition of insulin release seems to argue against an interference of thyroxine with phosphoglyceraldehyde dehydrogenase. This enzyme is inhibited by thyroid hormones [16]. It ap- pears possible that glyceraldehyde, dihydroxyacetone, and glyceric acid overcome the inhibition of secretion by providing the $\alpha$-ketoacid, pyruvate, via glycolysis. The inefficiency of lactate (Table 1) is in accord with this hypothesis, as the lactate dehydrogenase activity in the pancreatic islets is very low $[17,18]$. This may be relevant in vivo as blood pyruvate levels are increased in hyperthyroid rats [19]. $\alpha$-ketobutyrate is able to overcome the inhibition of glucose-induced insulin release after thyroxine treatment (Fig. 4 and Table 1), results which demonstrate that the ability of pyruvate to overcome the inhibition is apparently not due to pyruvate being a glycolytic substrate. $\alpha$-ketobutyrate is even more potent than pyruvate (Table 1). The $\alpha$-ketogroup is the moiety common to both substances and no common pathway appears to be known for pyruvate and $\alpha$-ketobutyrate. Neither is the effect of pyruvate due to its $\mathrm{C}_{3}$-structure or to the monocarboxylic acid moiety, as shown by the striking ineffectiveness of propionic acid (Table 1).

These characteristics of the inhibitory effect of thyroxine allow the conclusion that the reversibility of the inhibition of insulin release is at least to some extent specific for its sensitivity to $\alpha$-ketomonocarboxylic acids. These have been proposed to interact directly with receptor sites of the pancreatic B-cell [20], nevertheless the cellular mechanism of action of pyruvate and $\alpha$-ketobutyrate in connection with the inhibition of insulin secretion after thyroxine treatment remains unknown and requires further investigation. At present we cannot exclude intracellular effects of these ketoacids in their cellular actions.

Acknowledgement. The skilful technical assistance of Miss S. Detels and Miss R. Löffler is gratefully acknowledged. This work has been supported by the Deutsche Forschungsgemeinschaft.

\section{References}

1. Houssay, B.A.: The action of the thyroid on diabetes. Recent Progr. Hormone Res. 2, 277-291 (1948)

2. Lenzen, S., Joost, H.G., Hasselblatt, A.: Thyroid function and insulin secretion from the perfused pancreas of the rat. Endocrinology 99, 125-129 (1976)

3. Lenzen, S., Hasselblatt, A.: The effect of thyroxine treatment on the dynamics of insulin release from the isolated perfused rat pancreas. Naunyn-Schmiedeberg's Arch. Pharmacol. 282, 317-321 (1974)

4. Lenzen, S., Panten, U., Hasselblatt, A.: Thyroxine treatment and insulin secretion in the rat. Diabetologia 11, 49-55 (1975)

5. Lenzen, S., Joost, H. G., Beckmann, J., Hasselblatt, A.: Selective and reversible inhibition of glucose-induced insulin secretion caused by thyroxine treatment. Diabetologia 11, 359 (1975)

6. Grodsky, G.M., Batts, A. A., Bennett, L.L., Vcella, C., McWil- 
liams, N. B., Smith, P.F.: Effects of carbohydrates on secretion of insulin from isolated rat pancreas. Amer. J. Physiol. 205, 638-644 (1963)

7. Zaharko, D.S., Beck, L.V.: Studies of a simplified plasma insulin immunoassay using cellulose powder. Diabetes 17, 444-457 (1968)

8. Curry, D.L.: Fructose potentiation of mannose-induced insulin secretion. Amer. J. Physiol. 226, 1073-1076 (1974)

9. Malaisse, W.J., Herchuelz, A., Levy, J., Sener, A., Pipeleers, D.G., Devis, G., Somers, G., van Obberghen, E.: The stimulussecretion coupling of glucose-induced insulin release. XIX. The insulinotropic effect of glyceraldehyde. Molecular and Cellular Endocrinology 4, 1-12 (1976)

10. Loubatières-Mariani, M.M., Blayae, J.P., Alrich, R., Valette, G., Loubatières, A.: Effects of DL-lactate on insulin and glucagon secretions from the isolated and perfused pancreas. $C$. R. Soc. Biol. (Paris) 164, 1038-1044 (1974)

11. Matschinsky, F.M., Ellerman, J., Stillings, S., Raybaud, F., Pace, C., Zawallich, W.: Hexoses and insulin secretion. In: Handbook of experimental pharmacology, Vol. XXXII/2. Insulin II. (eds. A. Hasselblatt, F. v. Bruchhausen), pp. 87-114. Berlin-Heidelberg: Springer Verlag 1975

12. Curry, D. L., Bennett, L. L., Grodsky, G.M.: Dynamics of insulin secretion by the perfused rat pancreas. Endocrinology 83, 572-584 (1968)

13. Grodsky, G.M.: The kinetics of insulin release. In: Handbook of experimental pharmacology, Vol. XXXII/2. Insulin II. (eds. A. Hasselblatt, F. v. Bruchhausen), pp. 1-16. Berlin-Heidelberg: Springer Verlag 1975

14. Hellman, B., Idahl, L.-Å., Lernmark, Å., Sehlin, J., Täljedal, I.-B.: The pancreatic $\beta$-cell recognition of insulin secretagogues. Comparisons of glucose with glyceraldehyde isomers and dihydroxyacetone. Arch. Biochem. Biophys. 162, $448-457$ (1974)
15. Lenzen, S.: Studies on the inhibitory effect of thyroxine on insulin secretion from the perfused rat pancreas. NaunynSchmiedeberg's Arch. Pharmacol. 287, R 58 (1975)

16. Park, J.H., Koshland, D. E.: The hydrolytic activity of glyceraldehyde-3-phosphate dehydrogenase. J. biol. Chem. 233, 986-990 (1958)

17. Hellman, B., Täljedal, I.-B.: Quantitative studies on isolated pancreatic islets of mammals. Activity and heterogeneity of lactate dehydrogenase in obese-hyperglycemic mice. Endocrinology 81, 125-131 (1967)

18. Brolin, S.E., Berne, C., Linde, B.: Measurements of the enzymatic activities required for ATP formation by glycolysis in the pancreatic islets of hyperglycemic mice $(\mathrm{NZO})$. Diabetes 16, 21-25 (1967)

19. Hübner, G., Voss, C., Herrmann, R., Schwandtner, V.: Zum Verhalten des Lactat/Pyruvat-Quotienten im Blut von Ratten mit experimenteller Hyperthyroxinämie und Hypothyreose. Endokrinologie 63, 239-243 (1974)

20. Panten, U.: Effects of alpha-ketomonocarboxylic acids upon insulin secretion and metabolism of isolated pancreatic islets. Naunyn-Schmiedeberg's Arch. Pharmacol. 291, 405-420 (1975)

Received: April 20, 1976, and in revised form: June 24, 1976

Dr. Sigurd Lenzen

Institut für Pharmakologie

und Toxikologie

Universität Göttingen

Geiststr. 9

3400 Göttingen

Federal Republik of Germany 